\title{
Identification of molecular markers for Sw-5 gene of tomato spotted wilt virus resistance
}

\section{Ainong Shi ${ }^{1,2, *}$, Richard Vierling ${ }^{2,6, *}$, Richard Grazzini ${ }^{3}$, Pengyin Chen ${ }^{4}$, Homer Caton ${ }^{1}$, and Dilip Panthee}

${ }^{1}$ Syngenta Seeds, $2369330^{\text {th }}$ Street, Slater, IA50244, USA; ${ }^{2}$ Indiana Crop Improvement

Association and Department of Agronomy, Purdue University, West Lafayette, IN 47907, USA;

${ }^{3}$ GardenGenetics LLC, 131 Mendels Way, Bellefonte, PA 16823, USA; ${ }^{4}$ Department of Crop, Soil, and Environmental Sciences, University of Arkansas, Fayetteville, AR 72701, USA;

${ }^{5}$ Department of Horticultural Science, North Carolina State University, Mountain Horticultural Crops Research and Extension Center, NC 28759, USA.

${ }^{6}$ National Corn Growers Association 632 Cepi Drive Chesterfield, MO 63005. *Corresponding author: Ainong Shi (ainong.shi@syngenta.com or ainong shi@hotmail.com)

\section{ABSTRACT}

Tomato spotted wilt virus (TSWV) is one of the most destructive viral diseases that threaten worldwide tomato (Solanuum lycopersicum L. syn Lycopersicon esculentum Mill.) production. Use of host resistance appears to be the best way to control the disease. Marker assisted selection (MAS) has become very important and useful in the selection of TSWV resistance genes. The objective of this research was to identify $S w-5$ gene-specific PCR-based molecular markers and gene-derived single nucleotide polymorphism (SNP) markers for MAS in tomato breeding. A gene-specific PCR-based marker and two gene-derived SNP markers specific for TSWV resistance $S w 5-b$ allele were identified and validated in different tomato germplasm. It is expected that the present findings will be helpful in advancing the MAS for TSWV resistance in tomato.

Keywords: Disease resistance, $S W-5$, Single nucleotide polymorphism, Tomato, Tomato spotted wilt virus

\section{INTRODUCTION}

Tomato spotted wilt virus (TSWV) is one of the most destructive viral diseases that threaten worldwide tomato (Solanuum lycopersicum L. syn Lycopersicon esculentum Mill.) production (Saidi and Warade 2008). TSWV disease symptoms are often severe and include stunting and necrosis of stems and leaves (German et al. 1992). The virus is spread by thrips that transfer the virus from infected plants to healthy ones, causing plant systemic infection, reduced fruit yield, and unmarketable tomato fruits due to developing chlorotic and necrotic ringspots (German et al. 1992, Saidi and Warade 2008). Use of host resistance appears to be the best way to control the disease. So far, several genes for TSWV resistance have been reported (Sw1a, Sw1b, SW2, sw3, sw4, Sw-5, Sw-6, and Sw-7) (Finlay 1953, Price et al. 2007, Saidi and Warade 2008). Three recessive genes, sw2, sw3, and sw4, and the two dominant genes Sw1a and Sw1b were not used in commercial tomato production because resistance was quickly overcome (Price et al. 2007, Saidi and Warade 2008). Sw-6 conferred partial resistance to thrip inoculation and showed a narrower range for resistance to viral isolates than Sw-5 (Rosello et al., 1998, 2001). Recently, Sw-7 has been identified and introgressed from $L$. chilense LA 1938 into $L$. esculentum (Canady et al. 2001, Stevens et al. 2006, Price et al. 2007, Saidi and Warade 2008) and an amplified fragment length polymorphism (AFLP) marker was potentially identified to be linked to the gene (Price et al. 2007) and the gene was mapped on Chromosome 12 flanked by the markers T1263 (45.0 cM) and SSR20 (58.2 cM) (Stevens et al. 2009). SW-5 is the most broadly deployed TSWV resistance gene utilized in tomato breeding because of its durability to multiple tospoviruses (Boiteux and Giordano 1992, Stevens et al. 1992, 1994, 1995). The Sw-5 gene, first identified in L. peruvianum, also has provided stable resistance against TSWV isolates from different geographical locations (Boiteux 
and Giordano 1992, 1993, Stevens et al. 1992, 1994, 1996, Rosello et al. 1998).

Stevens et al. (1995) mapped Sw-5 between restriction fragment length polymorphism (RFLP) markers CT71 and CT220 near a telomeric region of chromosome 9 and also reported one random amplified polymorphic DNA (RAPD) marker 421R likely within $0.5 \mathrm{cM}$ of $S w-5$. Using a segregating $L$. esculentum backcross population derived from near isogenic lines (NILs), Stevens et al. (1996) further mapped the RAPD marker 421R linked to $S w-5$ within a distance of $1 \mathrm{cM}$ and the RFLP marker CT220 about $2.4 \mathrm{cM}$ from Sw-5. Chague et al. (1996) reported four RAPD markers linked to $S w-5$ within a distance of $10.5 \mathrm{cM}$ on chromosome 9 and one sequence characterized amplified region (SCAR) marker developed from the four RAPD makers. Five alleles (Sw5-a, Sw5-b, Sw5-c, Sw5-d, and Sw5-e) and seven $S w-5$ homologs distributed on chromosomes 9 and 12 were identified and cloned (Brommonschenkel and Tanksley 1997, Brommonschenkel et al. 2000). Among them, Sw5-b is the functional allele for conferring resistance to TSWV and its sequence was published in GenBank with the accession AY007366 (Spassova et al. 2001). AY007366 contains the sequence of the $L$. esculentum tospovirus resistance protein $A(S w 5-a)$ and tospovirus resistance protein B $(S w 5-b)$ genes. The tospovirus resistance protein A of the gene Sw5$a$ is complement to the sequence of the Sw-5 locus located at AY007366 from 20824 to 24561 base and the tospovirus resistance protein B of the gene Sw5-b is complement to the sequence of the Sw-5 locus located at AY007366 from 29513 to 33253 base (Folkertsma et al.1999, GenBank Accession AY007366). Garland et al. (2005) reported a dominant PCR-based marker representing the Sw-5 gene sequence co-segregated with the RFLP marker CT 220 (Stevens et al. 1995, 1996) in 50 individuals of an $\mathrm{F}_{2}$ mapping population.

Marker assisted selection (MAS) has been widely and successfully used in selecting disease resistance by identifying genetic markers that are linked to specific genes/alleles or combination of multiple resistance genes/alleles (Foolad and Sharma 2005, Foolad, 2007). Single nucleotide polymorphisms (SNPs), because of their abundance and highthroughput scoring potential, are becoming a powerful tool in genome mapping, association studies, diversity analysis, and tagging of important genes in plant genomics (Rafalski 2002, Giancola et al. 2006, Caicedo et al. 2007, Choi et al. 2007). SNPs have been discovered and verified in tomato (Yang et al. 2004, Labate and Baldo 2005) and successfully used in selection of resistance to bacterial speck and bacterial spot (Yang et al. 2005). The objective of this research was to identify Sw5- $b$ allele-specific PCRbased markers and gene-derived SNP markers for MAS in tomato breeding.

\section{MATERIALS AND METHODS}

Plant materials: Twenty-six tomato genotypes including released or commercial cultivars and accessions were used in this research (Table 1). Seeds of 14 tomato accessions (LA series) were obtained from the C.M. Rick Tomato Genetics Resource Center, Dept. of Plant Sciences, University of California, Davis, CA 95616 (http://tgrc.ucdavis.edu), 10 cultivars were purchased from commercial sources, and two lines NY07-461 and NY07-464 were obtained from Cornell University; refined selections from a cross between 'Brandywine' and 'Rose de Berne' (received as NY07-461 (Brandyrose c1) and NY07-464 (Brandyrose c2)). Among the 26 cultivars/accessions, three cultivars, Talladega (Rogers/Syngenta, Boise, ID), Sophya (Harris-Moran Seeds, Modesto, CA), and BHN-444 (BHN Seeds, Immokalee, FL) and accession LA3667 were purported by the company to have the TSWV resistance gene.

DNA extraction, PCR amplification and DNA sequencing: Genomic DNA was extracted from fresh leaves of greenhouse-grown plants using the CTAB (hexadecyltrimethyl ammonium bromide) method (Acciarri et al. 2007). PCR amplification was performed in an Eppendorf thermal cycler following standard PCR procedures with minor modifications. Briefly, each $50 \mu \mathrm{l}$ PCR reaction mixture consisted of $29.8 \mu \mathrm{l}$ sterilized $\mathrm{ddH}_{2} \mathrm{O}, 10 \mu \mathrm{l} 5 \mathrm{x}$ Mango $\mathrm{Taq}$ reaction buffer (Bioline, London, UK), $3 \mu \mathrm{MgCl}_{2}$ (25 $m M), 1.5 \mu \mathrm{ldNTP}$ (2.5 mM each), $1.5 \mu \mathrm{l}$ each primer $(5 \mu \mathrm{M}), 0.2 \mu \mathrm{l}$ Mango Taq DNA polymerase (5 $\mathrm{U} / \mu \mathrm{l})$ (Bioline, London, UK), and $2.5 \mu \mathrm{l}$ template DNA (30 $\mathrm{ng} / \mu \mathrm{l})$. For the primer pair Sw5-f1/r1 (Table 2), PCR procedure consisted of an initial denaturation step at $95^{\circ} \mathrm{C}$ for $1 \mathrm{~min}, 40$ cycles of 30 seconds at $94^{\circ} \mathrm{C}, 30$ seconds at $52^{\circ} \mathrm{C}$, and 1 min 15 seconds at $72^{\circ} \mathrm{C}$ followed by an extension step at $72^{\circ} \mathrm{C}$ for $5 \mathrm{~min}$ and a $4^{\circ} \mathrm{C}$ soak. For the primer pair Sw5-f2/r2, PCR procedure consisted of an initial denaturation step at $95^{\circ} \mathrm{C}$ for $1 \mathrm{~min}, 36$ cycles of 15 second at $94^{\circ} \mathrm{C}, 15$ second at $56^{\circ} \mathrm{C}$, and 45 second at $72^{\circ} \mathrm{C}$ followed by an extension step at $72^{\circ} \mathrm{C}$ for 5 min and a $4^{\circ} \mathrm{C}$ soak. The PCR fragments were separated by gel electrophoresis with $1.5 \%$ agarose gel in $0.5 \times$ TAE 
buffer, stained with ethidium bromide and visualized with UV light.

Sw-5 gene-specific primers were designed from the sequence of the GenBank accession AY 007366 using the primer design tool - Primer-BLAST (http://www.ncbi.nlm.nih.gov/tools/primerblast/index.cgi? LINK LOC=BlastHome).

The sequences of the two primers, Sw5-f1 and Sw5-r1 have two sites on AY007366, each in Sw5-a and Sw5- $b$, respectively, and the primers Sw5-f2 and Sw5-r2 are located only in the gene Sw5- $b$ sequence of the AY007366 (Table 2).

Table 1. Polymorphism of the four markers in the 26 tomato cultivars/accessions.

\begin{tabular}{|c|c|c|c|c|c|}
\hline Cultivar/Accession & $\begin{array}{l}\text { Gene at } \\
\text { Sw-5 locus }\end{array}$ & $\begin{array}{l}\text { Sw5- } \\
\text { f1/r1 }\end{array}$ & Sw5-f2/r2 & $\begin{array}{l}\text { Sw5- } \\
\text { snp1 }\end{array}$ & Sw5-snp2 \\
\hline Talladega & $S w 5-b^{a} \& S w 5-a$ & $+{ }^{b}$ & $+{ }^{c}$ & A $T$ & A A \\
\hline Sophya & $S w 5-b \&$ Sw5-a & + & + & A $T$ & A A \\
\hline BHN-444 & $S w 5-b \&$ Sw5-a & + & + & A T & $A A$ \\
\hline LA3667 & $S w 5-b \&$ Sw5-a & + & + & A $T$ & A A \\
\hline Anahu (LA0655) & $s w 5-b$ & + & - & A A & $G G$ \\
\hline LA0656 & $s w 5-b$ & + & - & $A$ A & $G G$ \\
\hline VFNT Cherry (LA1221) & $s w 5-b$ & + & - & A A & G G \\
\hline LA1802 & $s w 5-b$ & + & - & A A & G G \\
\hline Royal Red (LA2088) & $s w 5-b$ & + & - & A A & $G G$ \\
\hline Mobox (LA2821) & $s w 5-b$ & + & - & $A \quad A$ & G G \\
\hline Motella (LA2823) & $s w 5-b$ & + & - & A A & $G G$ \\
\hline UC-204C (LA3130) & $s w 5-b$ & + & - & $A \quad A$ & G G \\
\hline LA3432 & $s w 5-b$ & + & - & A A & G G \\
\hline LA3433 & $s w 5-b$ & + & - & A A & $G G$ \\
\hline Mogeor (LA3471) & $s w 5-b$ & + & - & $A \quad A$ & G G \\
\hline LA3473 & $s w 5-b$ & + & - & A A & $G \mathrm{G}$ \\
\hline Peto 95-43 (LA3528) & $s w 5-b$ & + & - & A A & $G G$ \\
\hline Bolseno & $s w 5-b$ & + & - & A A & $G G$ \\
\hline Riesentraube & $s w 5-b$ & + & - & A A & $G \mathrm{G}$ \\
\hline Tomatoberry & $s w 5-b$ & + & - & A A & G G \\
\hline Swt Cluster & $s w 5-b$ & + & - & A A & $G G$ \\
\hline Bush Celebrity & $s w 5-b$ & + & - & A A & G G \\
\hline Swt Chelsea & $s w 5-b$ & + & - & A A & $G \mathrm{G}$ \\
\hline Golden Girl & $s w 5-b$ & + & - & A A & $G \mathrm{G}$ \\
\hline NY07-461 & $s w 5-b$ & + & - & A A & G G \\
\hline NY07-464 & $s w 5-b$ & + & - & A A & G G \\
\hline
\end{tabular}

a Sw5- $b$ and Sw5-a are the resistance allele and $s w 5-b$ is the susceptible allele.

b ' + ' = the PCR fragment present and ' - ' = the PCR fragment absent.

${ }^{c}$ the SNP type such as [A T] signifies a heterogonous SNP type and [A A] signifies a homogenous SNP type. 
Am. J. Biotechnol. Mol. Sci., 2011, 1(1): 8-16

Table 2. Four primers and their characteristics.

\begin{tabular}{|c|c|c|c|}
\hline $\begin{array}{l}\text { Primer } \\
\text { name }^{a}\end{array}$ & Sequence ( $5^{\prime}-->3$ ') & $\mathrm{Tm}$ & $\begin{array}{l}\text { Location in } \\
\text { AY007366 }\end{array}$ \\
\hline \multirow{3}{*}{ Sw5-f1 } & & & $22369-22388$ \\
\hline & AACCACTAGGGGCAGTCCTT & 63.7 & $31061-31080$ \\
\hline & & & $23030-23011$ \\
\hline Sw5-r1 & СTCACTATGTGGCTGCTCCA & 64.1 & $31722-31703$ \\
\hline Sw5-f2 & CGGAACCTGTAACTTGACTG & 59.8 & 31414-31433 \\
\hline Sw5-r2 & GAGCTCTCATCCATTTTCCG & 59.8 & 31954-31935 \\
\hline
\end{tabular}

${ }^{a}$ Two forward primers, Sw5-f1, and Sw5-f2, and two reverse primers, Sw5-r1, and Sw5-r2 are designed from the GenBank accession AY007366 of the Sw-5 gene for tomato spotted wilt virus using the primer design tool PrimerBLAST.

${ }^{b}$ The primer location presenting the corresponding site in the GenBank accession AY007366. For example, the primer Sw5$\mathrm{f1}$ is located at 22369-22388 and 31061-31080 sites of the GenBank accession AY007366. AY007366 is the accession in GenBank that contains the sequence of the Lycopersicon esculentum tospovirus resistance protein A (Sw5-a) and tospovirus resistance protein B (Sw5-b) genes.

The PCR fragments amplified from the two primer pairs, Sw5-f1/r1 and Sw5-f2/r2, were sequenced in the Purdue Genomics Core Facility, Purdue University, West Lafayette, IN 47907 (http://www.genomics.purdue.edu/). Sequences amplified from the two primer pairs were submitted to GenBank using a DNA sequence submission and update tool $\quad-\quad$ Sequin (http://www.ncbi.nlm.nih.gov/Sequin/).

SNP identification and genotyping: The sequences amplified from the primer pair Sw5-f1/r1 were aligned using the software BioEdit (http://www.mbio.ncsu.edu/bioedit/bioedit.html).

SNP genotyping was done at the Sequenom Technology Core, the Division of Human Genetics in the Department of Genetics, Washington University, St. Louis, MO 63110 (http://hg.wustl.edu/info/Sequenom description.html ). Two SNPs were used for SNP genotyping all 26 tomato cultivars/accessions using Sequenom. The primers and the multiplex assay were list in Table 3.

\section{RESULTS}

PCR-based marker: The primer pair Sw5-f1/r1 produced a DNA fragment of 662 bp in all 26 tomato genotypes. This result indicated that the primer pair Sw5-f1/r1 amplified the specific sequence of the gene Sw-5 locus, and both the resistant and susceptible alleles at the Sw-5 locus were amplified by the primer pair. Therefore, this primer pair Sw5-f1/r1 can not be used to amplify a molecular marker for the selection of resistance gene Sw-5. However, a SNP/INDEL can be identified by comparing amplified sequences from resistance and susceptible alleles at Sw-5 locus among different genotypes. Using a similar method, Acciarri et al. (2007) identified a cleaved amplified polymorphic sequence (CAPS) marker for Ve2
Verticillium wilt resistance gene and $\mathrm{Yu}$ and Zou (2008) reported an InDel (insertion/deletion) marker for the Fusarium wilt resistance gene $I-2$ in tomato. The primer pair Sw5-f2/r2 produced a 541 bp fragment only in the four genotypes (Talladega, Sophya, BHN-444, LA3667) that contained the Sw5 gene, and not in the others (Table 1, Fig. 1). This result indicated that the primer pair Sw5-f2/r2 only amplified the resistance allele at the gene $S w-5$ locus and not the susceptible allele at the same locus, nor other loci. Therefore, the primer pair Sw5-f2/r2 can be used as a molecular marker in MAS for the gene Sw-5 in tomato breeding.

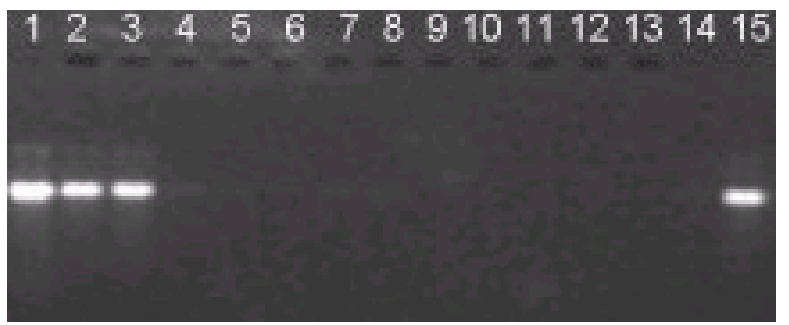

Fig. 1. PCR fragments (bands) with the size of 541 bp amplified from the primer pair Sw5-f2/Sw5-r2 among 15 tomato genotypes:

1. LA3667, 2. Talladega, 3. Sophya, 4. Anahu (LA0655),5. LA3433, 6. LA3473, 7, Mobox (LA2821), 8. Mogeor (LA3471), 9. Motella (LA2823), 10. Peto 95-43 (LA3528), 11 Royal Red (LA2088), 12. UC-204C (LA3130), 13. VFNT Cherry (LA1221), 14. NY07-464, and 15. BHN-444. 
Am. J. Biotechnol. Mol. Sci., 2011, 1(1): 8-16

Table 3. Primer properties in the SNP assay for Sequenom SNP genotyping.

\begin{tabular}{|c|c|c|c|c|c|c|}
\hline SNP_ID & $\begin{array}{l}\text { SNP }_{-} \\
\text {type }\end{array}$ & 2nd-PCRP & 1st-PCRP & $\begin{array}{l}\text { UEP } \\
\text { DIR }\end{array}$ & $\begin{array}{l}\text { UEP } \\
\text { MASS }\end{array}$ & UEP_SEQ \\
\hline $\begin{array}{l}\text { Sw5- } \\
\text { SNP1 }\end{array}$ & $\mathrm{A} / \mathrm{T}$ & ACGTTGGATGGGTATGGGATGACTTAAGGC & ACGTTGGATGACCCACTTCTTCAAGTCGAG & $\mathrm{R}$ & 6427.2 & gAAGGCTTTCTTTTCCAGATG \\
\hline $\begin{array}{l}\text { Sw5- } \\
\text { SNP1 }\end{array}$ & $A / G$ & ACGTTGGATGTTTCTCCTCAACATGTCGGC & ACGTTGGATGGAGAGAGTTATTACAAGAT & $\mathrm{F}$ & 5212.4 & AACATGTCGGCAAGAAC \\
\hline
\end{tabular}

Table 4. SNP type and location among five sequences of the five GenBank Accessions sequenced from five tomato cultivars/accessions.

\begin{tabular}{|c|c|c|c|c|c|c|c|c|c|c|c|c|c|c|}
\hline \multirow{2}{*}{$\begin{array}{l}\text { Cultivarl } \\
\text { Accession }\end{array}$} & \multirow{2}{*}{$\begin{array}{l}\text { Gene } \\
S w 5-b^{\mathrm{a}}\end{array}$} & \multirow{2}{*}{$\begin{array}{l}\begin{array}{l}\text { GenBank } \\
\text { accession }\end{array} \\
\text { AY007366 }\end{array}$} & \multicolumn{12}{|c|}{ SNP type and location in corresponding GenBank accession } \\
\hline & & & 31279 & $\mathrm{~T}$ & 31392 & $A$ & 31415 & C & 31417 & G & 31434 & G & 31459 & C \\
\hline LA3667 & $S w 5-b \& a$ & FJ686041 & 218 & $W^{b}$ & 331 & A & 354 & $Y^{b}$ & 356 & $\mathrm{R}^{\mathrm{b}}$ & 373 & G & 398 & $\mathrm{C}$ \\
\hline LA3433 & $s w 5 b$ & FJ686040 & 218 & $A$ & 331 & G & 354 & $\mathrm{~T}$ & 356 & $A$ & 373 & $A$ & 398 & $\mathrm{~T}$ \\
\hline LA2823 & $s w 5 b$ & FJ686039 & 218 & $A$ & 331 & G & 354 & $\mathrm{~T}$ & 356 & $A$ & 373 & $A$ & 398 & $\mathrm{~T}$ \\
\hline NY07-464 & $s w 5 b$ & FJ686042 & 218 & $A$ & 331 & G & 354 & $\mathrm{~T}$ & 356 & $A$ & 373 & $A$ & 398 & $\mathrm{~T}$ \\
\hline Stevens & Sw5-a & AY007366 & 22586 & $A$ & 22699 & $A$ & 22722 & $\mathrm{~T}$ & 22724 & $A$ & 22741 & G & 22766 & C \\
\hline
\end{tabular}

a The coding region of Sw5-a is located at 20824-24561 base and coding region of Sw5- $b$ at 29513-33253 base of the GenBank accession AY0073366 that was cloned from the tomato cultivar "Stevens" (Folkertsma et al 1999).

$\mathrm{b}^{\prime} \mathrm{W}$ ' = 'A/T', 'Y' = 'C/T', and 'R' = 'A/G'. 
Sequence analysis, SNP identification and genotyping: Four DNA fragments amplified from the primer pair Sw5-f1/r1 in LA2823, LA3433, LA3667, and NY07-464, respectively, were purified and sequenced in the Purdue Genomics Core Facility and the four sequences (Fig. 2) were stored in GenBank with the accessions FJ686039, FJ686040, FJ686041, and FJ686042. The sequences from LA2823, LA3433, and NY07-464 were 100\% nucleotide identity, which were $99 \%(656 / 662)$ identity to the corresponding sequence of the Sw5- $b$ allele at the site from 31061 to 31722 bases in AY007366 and $98 \%(654 / 663)$ identity to the sequence of the Sw5-a allele at the site from 22369 to 23030 bases in AY007366. The coding region of Sw5-a is located at 20824-24561 base and coding region of Sw5-b at 29513-33253 base of the GenBank accession AY0073366 (Folkertsma et al., 1999; Spassova et al., 2001). Comparing to sequences of Sw5-a or Sw5-b allele using BLAST (b/2seq) (http://blast.ncbi.nlm.nih.gov/bl2seq/wblast2.cgi), the sequence from LA3667 was 98\% (654/662) identity to Sw5-b and 98\% (653/662) to Sw5-a at corresponding site in AY007366.

From the multiple sequence alignment among the PCR fragments amplified from the primer pair Sw5$\mathrm{f} 1 / \mathrm{r} 1$ with the corresponding DNA segments of the Sw-5 resistance allele Sw5-b and Sw5-a (Fig. 2), six SNPs were observed between the sequences in LA2823, LA3433, and NY07-464, and the corresponding sequence of the $S w 5-b$ resistance allele at Sw-5 locus in AY007366 (Fig. 2 and Table 4). Because Sw5- $b$ was reported to be the functional allele for the TSWV resistance and Sw5-a was a homolog allele of Sw5-b located upstream of the Sw5- $b$ in GenBank Accession AY007366 (Folkertsma et al., 1999; Spassova et al., 2001), only the SNPs between the susceptible $s w 5-b$ and resistance allele Sw5- $b$ were of interest. The corresponding DNA segments of the Sw5 allele was used as a reference. Alignment analysis also indicated that the sequence amplified from Sw5-f1/r1 in LA3667 was a combination of two sequences with the same size from the corresponding site in Sw5-a and Sw5-b, respectively (Fig. 2), i.e. the primer pair Sw5-f1/r1 amplified two DNA fragments to corresponding sites of Sw5-a and Sw5-b simultaneously in LA3667. Results indicated that LA2823, LA3433, and NY07464 carried the susceptible sw5- $b$ allele and LA3667 carried both resistance Sw5-a and Sw5-b alleles.

Among the six SNPs in Table 4, the SNP [A/T] at the site 218 and the SNP [A/G] at the site 331 were verified by SNP genotyping using Sequenom among 26 tomato cultivars/accessions and the other four SNPs need to be further verified (Table 1). The three cultivars Talladega, Sophya, BHN-444, and the accession LA3667, which contain the resistance alleles Sw5-a and Sw5-b showed a heterozygous SNP genotype AT from the SNP marker Sw5-snp1 for the SNP $[A / T]$ at the site 218 and a homogenous genotype AA from the SNP marker Sw5-SNP2 for the SNP $[A / G]$ at the site 331 . The other 22 cultivars/accessions that did not contain the resistance $S w 5-b$ allele showed homozygous AA from Sw5-snp1 and GG from Sw5-snp2 (Table 1). The SNP genotyping further verified the results from the sequences amplified from Sw5-f1/r1, indicating that the base $T$ in Sw5-snp1 was specific for the resistance allele Sw5- $b$ and the base A in Sw5-snp1 for the susceptible allele $s w 5-b$ or for resistance allele Sw5-a and also indicating that the base A in Sw5snp2 was specific for the resistance allele Sw5-a or Sw5-b and the base G in Sw5-snp2 for the susceptible allele sw5-b. Two peaks at the 218 base, one $A$ and another $T$ were observed from the sequence (a trace file with .ab1 format) amplified from Sw5-f1/r1 in the resistance accession LA3667 $(S w-5 a+S w 5-b)$, indicating the base $A$ from the allele Sw5-a and T from allele Sw5- $b$ at the site 218 base. The SNP [A/T] was identified and verified in 26 tomato germplasm (Table 1 ).

Two DNA fragments amplified from the primer pair Sw5-f2/r2 in LA3667 and Talladega were purified and sequenced and the sequences of the fragments were also submitted to GenBank with the accession numbers FJ686043 and FJ686044. The sequences from LA3667 and Talladega were 100\% nucleotide identical, which had $100 \%(541 / 541)$ identity to the sequence from 31414 to 31954 base of AY007366 at the corresponding site of Sw5- $b$ resistance allele, further indicating that the primer pair Sw5-f2/r2 only amplified the resistance allele Sw5- $b$.

\section{DISCUSSION}

Molecular markers including RFLP, AFLP, RAPD, SCAR, CAPS and SNP have been identified and successfully used in selecting disease resistance in tomato, but most of them are linked to target genes of disease resistance (Foolad and Sharma 2005, Foolad, 2007). With more genes being cloned and sequenced, the sequence-derived PCR-based and SNP markers will be found easily for specific gene/allele. For Sw-5 gene of TSWV resistance, Garland et al. (2005) designed a pair of primers Sw5b-LRR-F and Sw-5b-LRR-R from leucine-rich-repeat 
(LRR) region of Sw5-b and identified this marker to be co-segregated with the RFLP marker CT 220 in 50 individuals of an $F_{2}$ mapping population. However, this primer pair was not designed from the sequence of $S w-5 b$ coding region. The primer Sw-5b-LRR-F (TCTTATATTGTGGAGTTTTTGTCG) in that paper is a reversal one and its reverse and complement sequence (CGACAAAAACTCCACAATATAAGA) is located at the bases from 30400 to 30377 base of the GenBank Accession AY007366. The primer Sw-5bLRR-R (TCCACCCTATCAAATCCAAC) is a forward one located at 30096 - 30115 bases of AY007366. The coding region of $S w 5-b$ is located at 2951333253 base of the GenBank accession AY0073366 (Folkertsma et al., 1999; Spassova et al., 2001). In this paper, we designed a primer pair Sw5-f2/Sw5-r2 from $S w-5 b$ coding region and this primer pair amplified a DNA fragment specific for Sw-5b and located at 31414 - 31954 base of AY0073366.

Although PCR based markers for Sw-5 gene have been described in previous papers, as well as already used in tomato MAS (Folkertsma et al. 1999, Garland et al. 2005), we not only identified new molecular markers specific for $S w-5 b$ but also provide an effective procedure to identify allele-specific PCRbased markers and gene-derived SNP markers for Sw5 in this research. Since it only amplifies DNA fragments from the lines carrying the resistance allele Sw-5, the primer pair Sw1- $\mathrm{f} 2 / \mathrm{r} 2$ could be used as a molecular marker in selection of the Sw5 gene in tomato breeding. However the primer pair sw5-f1/r1 produced DNA fragments in both resistant and susceptible lines, it could not be used as a molecular marker for MAS, but it could be used in SNP discovery and procedure of development of genespecific SNP markers for Sw-5 is showed in Fig. 3. The primer pair sw5-f1/r1 was designed from the Sw5 gene sequence (AY007366) using the tool PrimerBLAST and it can amplify the DNA sequence specific for the Sw-5 region and produced PCR products in both resistance and susceptible lines. Multiple sequence alignment among the PCR amplified fragments from Sw5-f1/r1 with the corresponding DNA segments of the $S w-5$ resistance allele Sw5-b and Sw5-a were used for SNP discovery among these sequences. These SNPs were verified using Sequenom SNP genotyping technology. Finally, one Sw5-b allele-specific PCR-based marker Sw5-f2/r2 and two Sw5-b gene-derived SNP markers were identified and verified in 26 tomato cultivars/accessions with known phenotypes. Furthermore, it was also used to amplify the DNA from two breeding lines with known reaction to TSWV from North Carolina State University. The DNA fragment was amplified in NC 0579(x)-43-7-4-1-1 (resistant to TSWV) whereas it did not amplify in NC 051(x)-66 (susceptible to TSWV), which verified the validity of the findings in independent genotypes. Therefore, these results will provide breeders a tool in MAS for Sw-5 gene or alleles of tomato spotted wilt virus resistance and also provide a method to identify allele-specific PCR-based markers and gene-derived SNP markers.
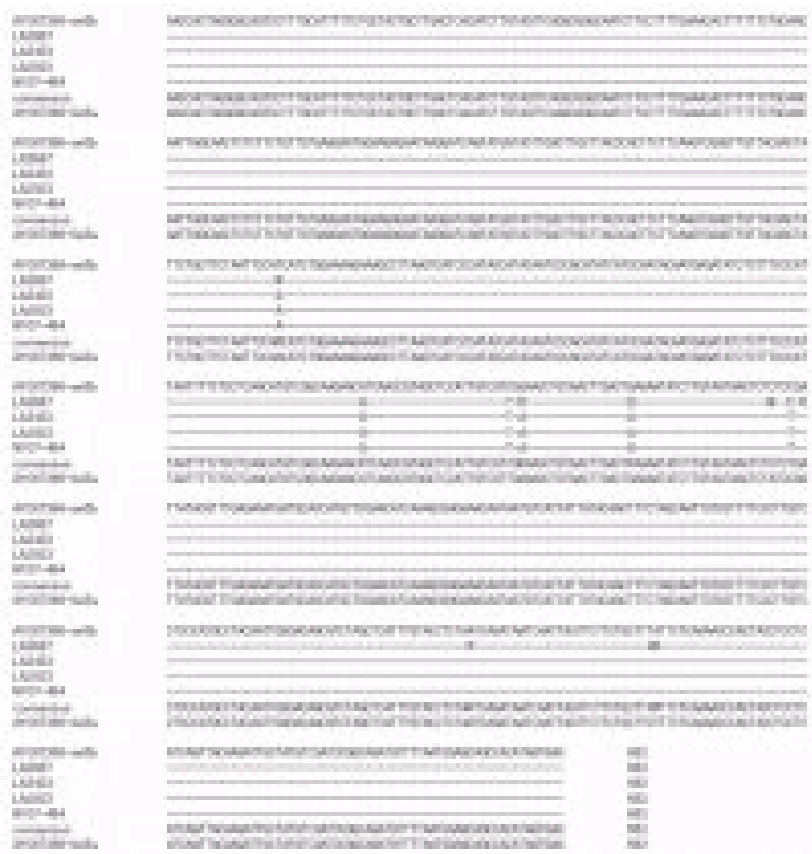

Fig. 2. Multiple sequence alignment among PCR fragments amplified from the primer pair Sw5-f1/r1 with the corresponding DNA segments of the Sw-5 resistance allele Sw5-b and Sw5-a. LA3667 is a resistant line contains the Sw-5 gene, but LA3433, LA2823 and NY07-464 are susceptible. AY007366-sw5b is the corresponding DNA segment of the Sw5-b resistance allele from the site 31061 to 31722 bases and AY007366-sw5a is the corresponding DNA segment of the Sw5-a resistance allele from the site 22369 to 23030 base of the GenBank accession AY007366. The consensus sequence is from the alignment of the six sequences except AY007366-sw5a. Dots represent sequence identity. 


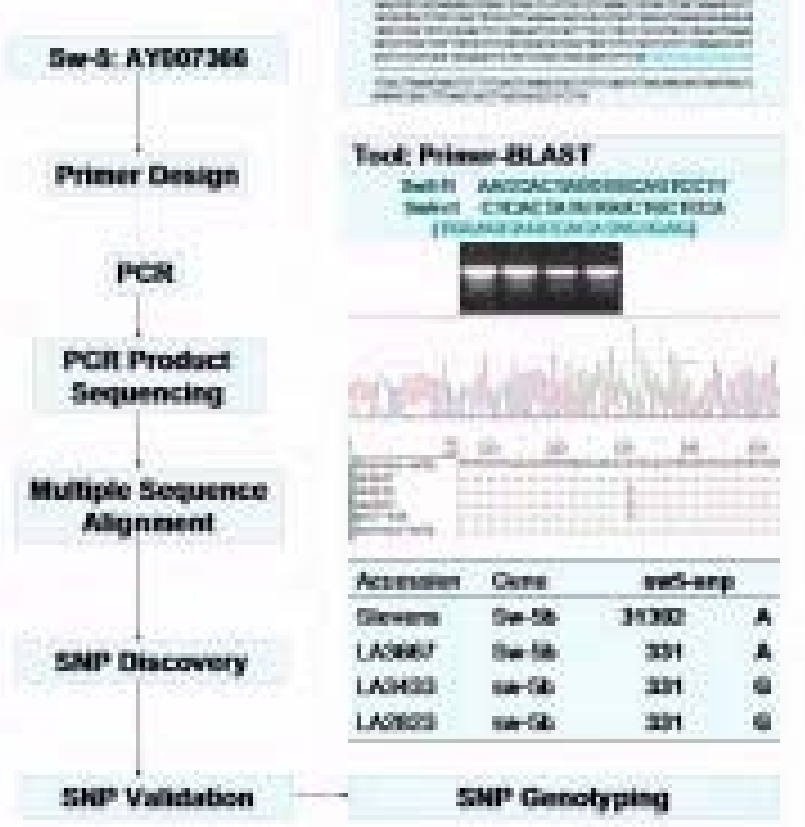

Fig. 3. Procedure of development of allele-specific SNP markers for Sw-5 in Tomato by use of PCR resequencing approach.

\section{ACKNOWLEDGEMENTS}

We thank G. Moriarty, M. Glos and M. Jahn (Cornell University) and C. R. Lawn (Restoring our Seed) for providing tomato line NY07-461 and NY07-464 that was developed with support from USDA-SARE proposal LNE04-204 and LNE02-160. We also thank Roger Chetelat and Sheh May Tam at Tomato Genetics Resource Center, Dept. of Plant Sciences, University of California for providing 14 tomato accessions. We are grateful to Dapeng Zhang at USDA-ARS for review of the manuscript.

\section{REFERENCES}

Acciarri, N., Rotino, G. L., Tamietti, G., Valentino, D., Voltattorni, S., and Sabatini, E. (2007). Molecular markers for Ve1 and Ve2 Verticillium resistance genes from Italian tomato germplasm. Plant Breeding 126: $617-621$.

Boiteux, L. S., and Giordano, L.de B. (1992). Screening Lycopersicon germplasm for resistance to a Brazilian isolate of spotted wilt virus (TSWV). Tomato Genet Coop Rep 42: 13-14.

Boiteux, L. S., Nagata, T., and Giordano, L.de B (1993). Field resistance of tomato Lycopersicon esculentum lines to tomato spotted wilt disease. Tomato Genetics Coop Rep 43: 7-9.

Brommonschenkel, S. H., Frary, A., Frary A., and Tanksley, S. D. (2000). The broad-spectrum tospovirus resistance gene $S w-5$ of tomato is a homolog of the root-knot nematode resistance gene Mi. Molecular Plant-Microbe Interaction 13: 1130-1138.

Brommonschenkel, S. H., and Tanksley, S. D. (1997). Mapbased cloning of the tomato genomic region that spans the Sw-5 tospovirus resistance gene in tomato. Molecular General Genetics 256:121-126.

CAICEDO, A. L., WILLIAMSON, S. H., and HERNANDEZ, R. D. (2007). Genome-wide patterns of nucleotide polymorphism in domesticated rice. PLoS Genetics 3:1745-56.

Canady, M. A., Stevens, M. R., Barineau, M. S. and Scott, J. W. (2001). Tomato spotted wilt virus (TSWV) resistance in tomato derived from Lycopersicon chilense Dun. LA 1938. Euphytica 117: 19-25.

Chague, V., Mercier, J. C., Guenard, M., De-Courcel, A., and Vedel, F. (1996). Identification and mapping on chromosome 9 of RAPD markers linked to $S w-5$ in tomato by bulked segregant analysis. Theoretical and Applied Genetics 92: 1045-1051.

Choi, I. Y., Hyten, D. L., and Matukumalli, L. K. (2007). A soybean transcript map: gene distribution, haplotype and single nucleotide polymorphism analysis. Genetics 176: 685-696.

Finlay, K. W. (1953). Inheritance of spotted wilt resistance in tomato. II. Five genes controlling spotted wilt resistance in four tomato types. Australian Journal of Biology Science 6: 153-163.

Folkertsman, R. T., Spassova, M. I., Prins, M., Stevens, M. R., Hille, J., and Goldbach, R. W. (1999). Construction of a bacterial artificial chromosome (BAC) library of Lycopersicon esculentum cv. Stevens and its application to physically map the Sw-5 locus. Molecular Breeding 5: 197-207.

Foolad, M. R. (2007). Genome mapping and of tomato. International J Plant Genomics. Article ID 64358, 52 pages (doi:10.1155/2007/64358)

Foolad, M. R., and Sharma, A. (2005). Molecular markers as selection tools in tomato breeding. Acta Hort 695: 225-240.

Garland, S., Sharman, M., Persley, A. D., and McGrath, D. (2005). The development of an improved PCR-based marker system for Sw-5, an important TSWV resistance gene of tomato. Australian Journal of Agricultural Research 56: 285-289.

German, T. L., Ullmand, D., and Moyer, J. W. (1992) Tospoviruses: Diagnosis, molecular biology, 
phylogeny, and vector relationships. Annual Review of Phytopathology 30: 315-348.

Giancola, S., McKhann, H. I., Berard, A., Camileri, C., Durand, S., Libeau, P., Roux, F., Rebound, X., Gut, I. G., and Brunel, D. (2006). Utilization of three highthroughput SNP genotyping methods, the GOOD assay, Amplifluor and Taqman, in diploid and polyploidy plants. Theoretical and Applied Genetics 112:1115-1124.

Latham, L. J., and Jones, R. A. C. (1998). Selection of resistance breaking strains of tomato spotted wilt tospovirus. Annual Applied Biology 133: 385-402.

Labate, J. A., and Baldo, A. M. (2005). Tomato SNP discovery by EST mining and resequencing. Molecular Breeding 16: 343-349.

McMichael, L. A., Persley, D. M., and Thomas J. E. (2002). A new tospovirus serogroup IV species infecting capsicum and tomato in Queensland. Australia Australasian Plant Pathology 31(3): 231-239.

Price, D. L., Memmott, F. D., Scott, J. W., Olson, S. M., and Stevens, M. R. (2007). Identification of molecular markers linked to a new tomato spotted wilt virus resistance source in tomato. Tomato Genetics Coop Rep (http://tgc.ifas.ufl.edu/vol57/html/vol57price.htm)

Rafalski, J. A. (2002). Application of single nucleotide polymorphisms in crop genetics. Current Opinion of Plant Biology 5: 94-100.

Rosello, S., Diez, M. J., and Nuez, F. (1998). Genetics of tomato spotted wilt virus resistance coming from Lycopersicon peruvianum. European Journal of Plant Pathology 5: 499-509.

Rosello, S., Ricarte, B., Diez, M. J., and Nuez, F. (2001). Resistance to tomato spotted wilt virus introgressed from Lycopersicon peruvianum in line UPV 1 may be allelic to $S w-5$ and can be used to enhance the resistance of hybrids cultivars. Euphytica 119: 357367.

Saidi, M., and Warade, S. D. (2008). Tomato breeding for resistance to tomato spotted wilt virus (TSWV): an overview of conventional and molecular approaches. Czech Journal of Genetics and Plant Breeding 44: 8392.

Scott, J. W., Stevens, M. R., and Olsen, S. M. (2005). An alternative source of resistance to tomato spotted wilt virus. Tomato Genetics Coop Rep 55: 40-41.
Spassova, M. I., Prins, T. W., Folkertsma, R. T., KleinLankhorst, R. M., Hille, J., Goldbach, R. W., and Prins, M. (2001). The tomato gene Sw5 is a member of the coiled coil, nucleotide binding, leucine-rich repeat class of plant resistance genes and confers resistance to TSWV in tobacco. Molecular Breeding 7: 151-161.

Stevens, M. R., Heiny, D. K., Rhoads, D. D., Griffiths, P. D., and Scott, J. W. (1996). A linkage map of the tomato spotted wilt virus resistance gene Sw-5 using near isogenic lines and an interspecific cross. Acta Hort (ISHS) 431: 385-392.

Stevens, M. R., Lamb, E. M., and Rhoads, D. D. (1995). Mapping the Sw-5 locus for tomato spotted wilt virus resistance in tomatoes using RAPD and RFLP analyses. Theoretical and Applied Genetics 90: 451456.

Stevens, M. R., Rhods, D. D., Lamb, E. M., Gergerich, R. C., and Morelock, T. E. (1993). Use of PCR and RFLP techniques to map the Sw-5 locus conferring resistance to tomato spotted wilt virus (TSWV) in tomatoes. HortScience 28: 583.

Stevens, M. R., Scott, J. W., Cho, J. J., Geary, B. D., and Memmott, F. D. (2006). A new dominantly inherited source of TSWV resistance in tomato derived from $L$. chilense, which resists isolates that overcome $S w-5$. HortScience 41: 991.

Stevens, M. R., Scott, S. J., and Gergerich, R. C. (1992). Inheritance of a gene for resistance to tomato spotted wilt virus (TSWV) from Lycopersicon peruvianum Mill. Euphytica 59: 9-17.

Stevens, M. R., Scott, S. J., and Gergerich, R. C. (1994). Evaluation of seven Lycopersicon species for resistance to tomato spotted wilt virus (TVSW). Euphytica 80: 79-84.

Yang, W., Bai, X., Kabelka, E., Eaton, C., Kamoun, S., vander-Knaap, E., and Franscis, D. (2004). Discovery of single nucleotide polymorphisms in Lycopersicon esculentum by computer aided analysis of expressed sequence tags. Molecular Breeding 14: 21-34.

Yang, W., Miller, S. A., Scott, J. W., Jones, J. B., and Ranscis, D. M. (2005). Ming tomato genome sequence databases for molecular markers: application to bacterial resistance and marker assisted selection. Acta Hort (ISHS) 695: 241-250.

Yu, S., and Zou, Y. (2008). A co-dominant molecular marker of Fusarium wilt resistance gene $1-2$ derived from gene sequence in tomato. Hereditas (Beijing) 30(7): 926-93. 